\title{
From the desk of General Secretary
}

Dear Friends,

It is a matter of great pleasure for the entire team of SAAPD, as they bring to you the first issue of the Journal of the association. With all due efforts, the dream to form a Regional organization catering to the South Asian population has finally been realized. The association aims to provide a platform, for the Pediatric Dentists of South Asian countries, to work together in a spirit of friendship, trust and understanding for the benefit of the children, and the society as a whole. The Society has established a useful and unique platform, to eradicate diseases of oral health in children that involves cooperation among South Asian countries.

The Journal of SAAPD will act as a means, for effective exchange of ideas and skills, among dental professionals catering to various striates, across the nation. We hope to build a consortium, where one can benefit from the other, as a whole and services can be provided at a wider forum. This Journal wishes to receive and acknowledge, the various scientific researches carried out by dentists from across the South Asian subcontinent. As we all know that the prevalence and burden of oral diseases is high among the South Asian countries, still there is a lack of coherent scientific content and valuable researches, proving to be a limitation in instigating early treatment and prevention regarding the same. Through this Journal, we aim to bridge the gap between provision of treatment and the omnipresent diseases in our nations.

It is vitally important that, researcher in the field of Pediatric Dentistry have an international forum, through which they can share their work and experiences, especially when such information can help save or improve the status of oral health of children. In this era of digital world, this new open access online journal will strengthen the ties, between the international communities of Pediatric Dentistry.

There are extensive options for authors, to argument the presentation of their research in JSAAPD, for instance by including their underlying data presented in interactive graphs, or using 3-D visualization of work done.

"As children are the future of any country, a healthy oral cavity will definitely lead to a healthy body, making the future a prosperous and a progressive one". With this thought,

I wish to place on record and express gratitude for voluntary scientific contribution, in editorial process made by editorial board, which is comprised of a well-balanced representation from each participant country, for the inaugural issue of the journal.

Finally, I hope and wish that this Journal will prove to be a valuable asset and will fulfil its purpose at large

Dr Gyanendra Kumar

Secretary 